\title{
A Study on Effects of Project Manager Consultants' Competencies on Consulting Performance and Satisfaction - Focused on Moderating Effects on Client Enterprises' Level of Participation
}

\author{
Jung-Min Kim ${ }^{1}$, Jin-Teak Jung ${ }^{2 *}$ and Seok-Kee Lee ${ }^{3}$ \\ 'Department of Knowledge Service and Consulting, Hansung University, Seoul, Korea; \\ saintjmk@gmail.com \\ 2Department of Public Administration, Hansung University, Seoul Korea; \\ jungjt@hansung.ac.kr \\ ${ }^{3}$ Department of Industrial Management and Engineering, Hansung University, Seoul, Korea; \\ seelee@hansung.ac.kr
}

\begin{abstract}
Objectives: This study attempted to survey the PM consultants playing a role as a leader in the consulting project that government has funded in respond to the recent business environment. Methods/Statistical Analysis: A survey and analysis were conducted by recruiting representatives or staffs responsible for consulting out of 900 SMEs that had participated the coupon system consulting project conducted as part of the policy to revitalize SMEs. The survey was carried out via e-mail from September 15 to October 20, 2011. 5. For 5 kinds of questions on client enterprises, 21 kinds of questions related to PM consultant competencies and consulting performance, and 3 kinds of questions on satisfaction. Single-dimensionality analysis was conducted using the SPSS19.0 package. Findings: The findings demonstrated that PM consultants' competencies affects interpersonal abilities and their management abilities have an influence on consulting performance, implying that client enterprises' level of participation moderates the performance. This suggests that both PM consultants' interpersonal and management abilities are important in order for client small - medium sized enterprises (SMEs) to experience the consulting performance and satisfaction concerning the consulting support project enforced by the government. Application/Improvements: To bring about the expected effects from the governmental supporting consulting project aimed for SMs to raise competitiveness, the current system must be institutionally complemented to ensure PM consultants equipped both with interpersonal and management abilities are input.
\end{abstract}

Keywords: Client Enterprises' Level of Participation, Consulting for Small-medium Sized Enterprises, Consulting Performance, Consulting Satisfaction, PM Consultants Competencies,

\section{Introduction}

The recent business environment shows a trend of an increase in the enterprises being globalized through the innovation to change the previous paradigm; their innovation features an evolution seeming one, not a kind of transformation, as if all of organs must be changed into lung from gill breathing when a tadpole experiences metamorphosis into a frog.

Such a good example is that Steve Jobs of Apple launched the iPhone that completely changed the concept of traditional mobile phones which then became popularized with the worldwide recognition as a creative product. In line with

${ }^{*}$ Author for correspondence 
this, innovative CEOs include Steve Jobs of Apple, as well as Facebook Mark Zuckerberg, Amazon Jeff Bezos, and Tesla Alan Musk called the second Steve Jobs, all of whom are globally recognized as the innovative leader.

Korean government has supported Small-medium Sized Enterprises (SMEs) with the government's budget gradually increasing ( 12.5 billion in 2012, 12.8 billion in 2013, and 13.2 billion won in 2014) as part of its policy to allow them to respond to technologic and environmental changes and thus to raise their productivity and competitiveness through experts' diagnosis and guidance (www.smbacon.go.kr).

In this regard, studies on consulting service quality, satisfaction, and performance have been conducted as part of the consulting support project for which the government has supported the annual budget. At this point then, there is the need to confirm what effects PM consultants' competencies as a leader in the governmental supporting consulting project in respond to the recent business have on consulting performance and consulting satisfaction environment.

\section{Theoretical Background}

\subsection{Leadership Competency}

In one of the prior domestic studies $\frac{1}{}$, divided competencies necessary for IT project managers into professional knowledge and skills, interpersonal relationship knowledge and skills, and integrated, conceptualized knowledge and skills. In ${ }^{2}$ divided competencies necessary for project managers into a management competency, a personal competency, and a team management competency. She defined the management competency as a capability to manage the project knowledge area, the personal competency as a capacity including an understanding and practical experience of project-related business issues, and the team management competency, including the leadership of forming teamwork, leading the team, and motivating the team members and a human resources management capability to effectively managing the team members. $\mathrm{In}^{3}{ }^{3}$ and ${ }^{4}$ divided project leaders' competencies into an emotional competence, a cognitive competence and a social competence. According their definitions, the emotional competence means the project leaders' qualities including directional efficiency, planning, business leadership, self-discipline, flexibility, etc. The cognitive competency refers to an ability to perform projects, including project-related knowledge and conceptualization, systemic thinking, and task pattern cognition. The social competence includes an ability of empathy, negotiation, and persuasion by allowing the project leaders to interact with team members, forming a network, and making communication, and an ability to develop and manage team members' skills. Lastly,, divided transformational and emotional leadership.

\subsection{Consulting Performance}

In his study on "Effects of Consultants' Competences on Consulting Service Quality and Customer Satisfaction ${ }^{6}$," verified the relationship between two variables by setting consultants as an independent variable and consulting services quality as a dependent variable. In his study on an influence of consults' competencies on customer satisfaction and renewal intentions, ${ }^{\underline{Z}}$ examined the relationship between two variables by designing consultants' competencies as an independent variable and consulting service trust as a dependent variable.

\subsection{Consulting Satisfaction}

The lexical meaning of satisfaction is "satisfied in mind, sufficient without lacking." Therefore, customer satisfaction, a marketing- centered concept, has been related to several corporate performances since the 1970s. This term has been treated as an important issue in academia and business community. In general, customer satisfaction is known to occur when the benefit that the customer gets is higher than the cost that the customer has paid. In ${ }^{8}$ asserted that SMEs' participation in consulting affects consulting utilization and consulting agencies' capabilities. He also found that consultants' competencies have an influence on SMEs' consulting satisfaction and utilization. $\mathrm{In}^{9}$ reported that consulting satisfaction is higher in the cost reduction through management consulting; customer performance satisfaction is higher in the improvement of customer management competencies through consulting; and internal management performance is higher in the environmental improvement of production spots through management consulting. In terms of a form of consulting for SMEs, short-term consulting constitutes the mainstream. An area of consulting for SMEs accounted for production management mainly, followed by system and certification, and spot improvement. However, consulting effects were found to be moderate rather than retained.

\section{Setting Research Model and Hypotheses}

\subsection{Research Model}

Based on the embodied concepts and theoretical backgrounds presented by leading researchers, this study set the following research mode to analyze what influence PM 
consultants' competencies has on consulting performance and consulting satisfaction and to confirm moderating effects according to client enterprises' participation, The model is illustrated in Figure 1.

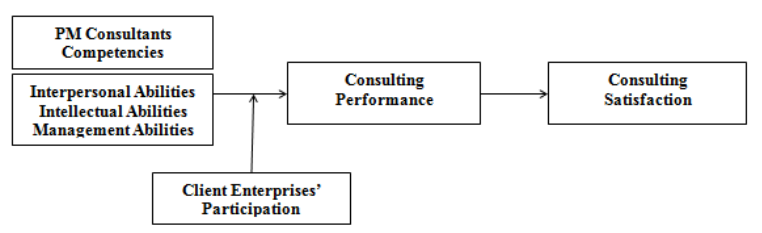

Figure 1. Research model.

\subsection{Setting Research Hypotheses}

In his study on "Effects of Consultants' Competencies on Consulting Performance by means of Service Quality ${ }^{5}$," demonstrated that consultants' competences affect consulting performance.

In addition, the previous studies have found that consulting services quality is a main factor that affects consulting satisfaction. In her study on "Effects of Key elements of SMEs on Consulting Performance ${ }^{10}$," divided consultants' competences into capabilities, knowledge, and attitudes, and analyzed the relationship between the four elements and consulting satisfaction. The results found that consultants' knowledge and attitudes, except for capabilities, have a positive relationship with consulting satisfaction.

Based on the previous studies, an inference can be made that PM consultants 'competences will affect consulting performance and consulting satisfaction, directly or indirectly. In this sense, there is the need to confirm what influence client enterprises' resistance, namely, participation, has on consulting performance and consulting satisfaction. Thus, this study set the following hypotheses, based on the previous studies.

H1. PM competencies consultants will have a positive (+) influence on consulting performance.

H2. PM competencies affecting consulting performance will be moderated depending on client enterprises' level of participation.

H3. Consulting performance will have a positive (+) influence on consulting satisfaction.

\section{Method}

\subsection{Population and Sample Selection}

The population consisted of consulting -experienced enterprises selected among SMEs in Korea. For the sample, all the domestic SMEs were evenly arranged by industry sector and region. A survey and analysis were conducted by recruiting representatives or staffs responsible for consulting out of 900 SMEs that had participated the coupon system - consulting project conducted as part of the policy to revitalize SMEs. The survey was carried out via e-mail from September 15 to October 20, 2011. 5.

\subsection{Configuration and Analysis of the Survey}

In this study, the questionnaires of the survey for the empirical analysis were based on the existing literature and consisted of questions on PM consultants' competencies, and consulting performance, and consulting satisfaction that SMEs think of, as well as other questions suitable for characteristics of client enterprises. The questionnaire was carried out by self-report of allowing the respondent to respond himself. It was composed of a total of 34questions in 4 categories (Table 1). For the 2 sectors, expect for general characteristics of SMEs that received consulting service, the Likert 5-point scale (not at all-not-fair-yes-strongly agree) was used.

\section{Empirical Analysis and Verification}

\subsection{Data Collection}

In order to verify this study, a total of 900 questionnaires were distributed. Of these questions, 261(29\%) were recollected. Expect for the 51questions in which respondents gave a perfidious answer, finally, 210questions (80.5\%) were used for the validation of this study.

\subsection{Single-dimensional and Reliable Verification}

For 5 kinds of questions on client enterprises, 21 kinds of questions related to PM consultant competencies and consulting performance, and 3 kinds of questions on satisfaction. Single-dimensionality analysis was conducted using the SPSS19.0 package. The factor loading of client enterprises' level of participation was analyzed into one 
Table 1. Configuration of the survey

\begin{tabular}{|c|c|c|c|c|}
\hline \multicolumn{2}{|l|}{ Segment } & $\begin{array}{l}\text { Number of } \\
\text { Questions }\end{array}$ & Sources & Scale \\
\hline \multicolumn{2}{|c|}{ Client Enterprises Level of Participation } & 5 & Gwak Hong-joo MOng-joo(5) & \multirow{6}{*}{$\begin{array}{l}\text { Likert type } \\
5 \text {-point scale }\end{array}$} \\
\hline \multirow[t]{3}{*}{$\begin{array}{l}\text { PM } \\
\text { Consultant's } \\
\text { Competencies }\end{array}$} & $\begin{array}{l}\text { Interpersonal } \\
\text { Abilities }\end{array}$ & 7 & $\begin{array}{l}\text { Lampell (2001), Moon Yonge-eun (2003) } \\
\text { Dulewicz \& Higgs (2005), } \\
\text { Boyatzis \& Ratti (2007), Muller \& Turner } \\
\text { (2007), } \\
\text { Geoghegan \& Dulewizc(2008) }\end{array}$ & \\
\hline & $\begin{array}{l}\text { Intellectual } \\
\text { Abilities }\end{array}$ & 5 & $\begin{array}{l}\text { Dulewicz \& Higgs(2005), } \\
\text { Kim Eun-hong \& Kim Hwa-young (2006), } \\
\text { Muller \& Turner(2007), } \\
\text { Geoghegan \& Dulewizc(2008) }\end{array}$ & \\
\hline & $\begin{array}{l}\text { Management } \\
\text { Abilities }\end{array}$ & 5 & $\begin{array}{l}{ }^{1} \text { Moon Yonge-eun (2003), } \\
\text { Dulewicz \& Higgs(2005), } \\
\text { Lee Seok-jae(2006), Tylor(2006), Ahn Jae- } \\
\text { seong(2007), Han Yeon- ok(2007), } \\
\text { Muller \& Turner(2007), } \\
\text { Geoghegan \& Dulewizc(2008) }\end{array}$ & \\
\hline \multicolumn{2}{|c|}{ Consulting Performance } & 9 & $\begin{array}{l}\text { Pinto \& Prescott (1990) } \\
\text { Slevin \& Pinto (1987) } \\
\text { Zand \& Sorensen (1975) } \\
\text { Jang Young (1996) }\end{array}$ & \\
\hline \multicolumn{2}{|c|}{ Consulting Satisfaction } & 3 & $\begin{array}{l}\text { Joe Chul-ho (2004), Lim Ho-soon (2005) } \\
\text { 1,Jang Dong-in (2011) }\end{array}$ & \\
\hline
\end{tabular}

factor with 0.5 or higher. Concerning PM consultants' competencies including interpersonal abilities, intellectual abilities, and management abilities, the single dimension was analyzed into 2 factors with 0.6 or higher in the factor loading. Thus, since questions on PM consultants' interpersonal abilities and intellectual abilities significantly overlap with each other, so reanalysis was conducted, except for questions related to PM consultants' intellectual abilities. In addition, consulting performance and consulting satisfaction were extracted into one factor. The principal component analysis found 4 factors with 1 or higher in eigenvalue, as shown in Table 2.

On the other hand, Cronbach a coefficient was analyzed to determine the reliability of construct validity proven through the factor analysis. The results found 0.7 or higher in Cronbach a coefficient, suggesting that the reliability of all the variables has been sufficiently obtained.

\subsection{Hypothesis Testing and Interpretation of Results Interpretation}

Based on the research model, verification was conducted to see whether PM consultants' competencies affect consulting performance and satisfaction or not. In addition, regression analysis was conducted to verify whether or not client enterprises' level of participation plays a moderating role in the process when PM consultants' competencies affect consulting performance.

Control regression analysis was conducted to confirm whether or not moderating effects are available in the relationship between PM consultants' interpersonal abilities and consulting performance according to client enterprises' level of participation (Table 3). In this analysis, if client enterprises' level of participation was higher than the average 3.7552 , they were identified into the actively participating group, and if lower than 3.7552, they were into the passive participating group. The data obtained were converted into dummy variables and analyzed.

Firstly, effects of independent variables on dependent variables were verified. The analysis of the effects of consultants' interpersonal abilities on consulting performance found 0.619 in R-squared value. This implies that $61.9 \%$ of the total variation is explained by the regression model. PM consultants' interpersonal abilities showed 18.397 in $t$ value and 0.000 in significant probability for consulting performance. This implies that PM 
Table 2. Exploratory factor analysis and criticality analysis

\begin{tabular}{|c|c|c|c|c|c|c|c|}
\hline \multirow[t]{2}{*}{ Constructs } & \multirow{2}{*}{$\begin{array}{l}\text { Number of } \\
\text { measurement items }\end{array}$} & \multirow{2}{*}{$\begin{array}{c}\text { Number of } \\
\text { items after } \\
\text { oblique rotation }\end{array}$} & \multicolumn{4}{|c|}{ Factor Loading } & \multirow{2}{*}{$\begin{array}{c}\text { Cronbach } \\
\text { a }\end{array}$} \\
\hline & & & Factor 1 & Factor 2 & Factor 3 & Factor 4 & \\
\hline \multicolumn{2}{|c|}{$\begin{array}{l}\text { Participation of client enterprises' } \\
\text { participation (5) }\end{array}$} & 5 & $\begin{array}{l}0.710 \\
0.701 \\
0.661 \\
0.608 \\
0.571\end{array}$ & & & & 0.912 \\
\hline \multirow[t]{2}{*}{$\begin{array}{l}\text { PM } \\
\text { consultants' } \\
\text { competencies }\end{array}$} & $\begin{array}{l}\text { Interpersonal abilities } \\
(7)\end{array}$ & 7 & & $\begin{array}{l}0.786 \\
0.767 \\
0.764 \\
0.729 \\
0.725 \\
0.716 \\
0.629\end{array}$ & & & 0.937 \\
\hline & $\begin{array}{l}\text { Management abilities } \\
\text { (5) }\end{array}$ & 5 & & & $\begin{array}{l}0.809 \\
0.758 \\
0.753 \\
0.752 \\
0.718 \\
\end{array}$ & & 0.947 \\
\hline \multicolumn{2}{|c|}{$\begin{array}{l}\text { Consulting performance } \\
\text { (13) }\end{array}$} & 9 & & & & $\begin{array}{l}0.898 \\
0.894 \\
0.892 \\
0.854 \\
0.815 \\
0.813 \\
0.746 \\
0.688 \\
\end{array}$ & 0.979 \\
\hline \multicolumn{2}{|l|}{ Satisfaction (3) } & 3 & & & & $\begin{array}{l}0.811 \\
0.809 \\
0.774\end{array}$ & \\
\hline \multicolumn{3}{|l|}{ Eigen value } & 1.050 & 3.155 & 1.588 & 17.207 & \\
\hline \multicolumn{3}{|c|}{$\%$ of Dispersion explained } & 3.621 & 10.879 & 5.477 & 59.366 & 79.313 \\
\hline
\end{tabular}

Kaiser-Meyer-Olkin Arcs : 0.956

Significance Probability : 0.000

consultants' interpersonal abilities have a statistically significant influence on consulting performance. In this regard, the standardization factor was found to be 0.787 .

Secondly, multiple regression analysis was conducted for dummy variables of PM consultants' interpersonal abilities and client enterprises' level of participation to analyze an influence of independent variables and moderate variables on Dependent variables. The results found 0.19 in the variation of R-squared value, compared to the R-squared value of PM consultants' interpersonal abilities and consulting performance. This implies that the total variation is explained by the regression model with 0.635 , an increase of $1.9 \%$. At this point, PM consultants' interpersonal abilities were found to have a significant influence on consulting performance with 13.509 in t value and 0.000 in significant probability. In this regard, the standardized coefficient was observed to be 0.690 . Client enterprises' level of participation was found to have a statistically significant influence on consulting performance with 3.282 in $t$ value and 0.000 in significant probability, and the standardized coefficient showed 0.690 .

Lastly, the analysis of effects on the dependent variable was carried out by adding independent variables, control variables, and interaction terms. As a result, the variation of the modified R-squared value turned out 0.041 . This 
Table 3. Moderating regression result on PM consultants' interpersonal abilities and consulting performance Model summary

\begin{tabular}{|c|c|c|c|c|c|c|c|c|c|}
\hline \multirow[t]{2}{*}{ Model } & \multirow[t]{2}{*}{$\mathrm{R}$} & \multirow[t]{2}{*}{$\mathrm{R}^{2}$} & \multirow[t]{2}{*}{ Adj. $\mathrm{R}^{2}$} & \multirow{2}{*}{$\begin{array}{c}\text { Estimated } \\
\text { SE }\end{array}$} & \multicolumn{5}{|c|}{$\Delta$ Statistics } \\
\hline & & & & & $\Delta \mathrm{R}^{2}$ & $\Delta \mathrm{F}$ & dfl & $\mathrm{df} 2$ & $\begin{array}{c}\text { Significant } \\
\text { Prob. } \\
\Delta \mathrm{F}\end{array}$ \\
\hline 1 & $0.787^{a}$ & 0.619 & 0.618 & .55706 & 0.619 & 338.458 & 1 & 208 & 0.000 \\
\hline 2 & $0.799^{b}$ & 0.638 & 0.635 & .54441 & 0.019 & 10.773 & 1 & 207 & 0.001 \\
\hline 3 & $0.824^{c}$ & 0.680 & 0.675 & .51350 & 0.041 & 26.679 & 1 & 206 & 0.000 \\
\hline
\end{tabular}

a. Predicted value: (Constant), PM interpersonal abilities

b. Predicted value: (Constant), PM interpersonal abilities, Level of participation

c. Predicted value: (Constant), PM interpersonal abilities, Level of participation, PM interpersonal abilities ${ }^{\star}$ Level of participation

\begin{tabular}{|c|c|c|c|c|c|c|}
\hline \multicolumn{7}{|c|}{ ANOVA $^{\mathrm{d}}$} \\
\hline \multicolumn{2}{|c|}{ Model } & Sum of Square & df & Avg. square & $\mathrm{F}$ & $\mathrm{p}$ \\
\hline \multirow[t]{3}{*}{1} & Regression Model & 105.028 & 1 & 105.028 & 338.458 & $0.000^{\mathrm{a}}$ \\
\hline & Residual & 64.545 & 208 & 0.310 & & \\
\hline & Total & 169.573 & 209 & & & \\
\hline \multirow[t]{3}{*}{2} & Regression Model & 108.221 & 2 & 54.111 & 182.567 & $0.000^{\mathrm{b}}$ \\
\hline & Residual & 61.352 & 207 & 0.296 & & \\
\hline & Total & 169.573 & 209 & & & \\
\hline \multirow[t]{3}{*}{3} & $\begin{array}{l}\text { Regression } \\
\text { Model }\end{array}$ & 115.256 & 3 & 38.419 & 145.702 & $0.000^{c}$ \\
\hline & Residual & 54.316 & 206 & 0.264 & & \\
\hline & Total & 169.573 & 209 & & & \\
\hline
\end{tabular}

a. Predicted value: (Constant), PM interpersonal abilities

b. Predicted value: (Constant), PM interpersonal abilities, Level of participation

c. Predicted value: (Constant), PM interpersonal abilities, Level of participation, PM interpersonal abilities* Level of participation

d. Dependent Variable: Consulting Performance

Coefficient $^{\mathrm{a}}$

\begin{tabular}{|c|c|c|c|c|c|c|}
\hline & & \multicolumn{2}{|c|}{$\begin{array}{c}\text { Non Standardized } \\
\text { Coefficient }\end{array}$} & \multirow{2}{*}{$\begin{array}{c}\begin{array}{c}\text { Standardized } \\
\text { Coefficient }\end{array} \\
\beta\end{array}$} & \multirow[t]{2}{*}{$\mathrm{t}$} & \multirow[t]{2}{*}{$\mathrm{p}$} \\
\hline & & B & SE & & & \\
\hline \multirow[t]{2}{*}{1} & (Constant) & 0.494 & 0.191 & & 2.585 & 0.010 \\
\hline & PM interpersonal abilities & 0.850 & 0.046 & 0.787 & 18.397 & 0.000 \\
\hline \multirow[t]{3}{*}{2} & (Constant) & 0.735 & 0.201 & & 3.664 & 0.000 \\
\hline & PM interpersonal abilities & 0.745 & 0.056 & 0.690 & 13.509 & 0.000 \\
\hline & Level of Participation & 0.307 & 0.093 & 0.168 & 3.282 & 0.001 \\
\hline \multirow[t]{4}{*}{3} & (Constant) & 0.083 & 0.228 & & 0.364 & 0.716 \\
\hline & PM interpersonal abilities & 0.933 & 0.063 & 0.864 & 14.701 & 0.000 \\
\hline & Level of Participation & 2.673 & 0.467 & 1.463 & 5.729 & 0.000 \\
\hline & $\begin{array}{l}\text { PM interpersonal abilities } \\
{ }^{*} \text { Level of Participation }\end{array}$ & -0.573 & 0.111 & -1.417 & -5.165 & 0.000 \\
\hline
\end{tabular}

a. Dependent Variable: Consulting Performance 
implies that $68 \%$ of the total variation is explained by the regression model with 0.0680 with an increase of $4.1 \%$. At this point, $\mathrm{PM}$ consultants' interpersonal abilities were found to have a significant influence on consulting performance with 14.701 in $t$ value and 0.000 in significant probability. In this regard, the standardized coefficient was .864. Additionally, client enterprises' level of participation was found to have a significant influence on consulting performance with 5.729 in $t$ value and 0.000 in significant probability. In this regard, the standardized coefficient was found to be 1.463 . Additionally, the interaction between PM consultants' interpersonal abilities and client enterprises' participation showed 5.729 in $t$ value and 0.000 in $t$ value, which have a statistically significant influence on consulting performance. In this regard, standardized coefficient was found to be -1.417 .

Therefore, in the process when PM consultants interpersonal abilities as a similar moderator variable having a significant effect on dependent variables, client enterprises' level of participation moderates consulting performance according their active or passive attitude in Figure 2.

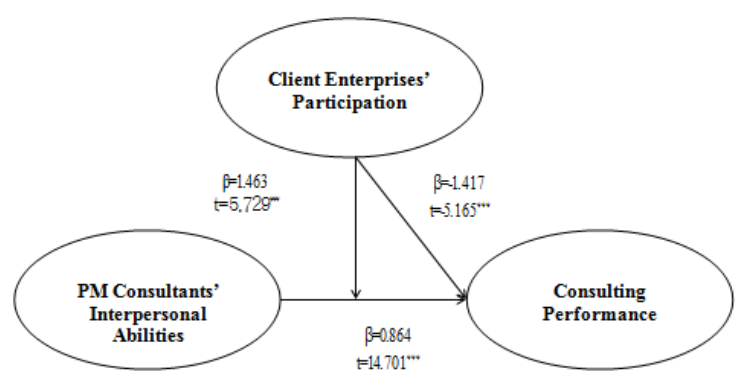

Figure 2. Moderating effects of level of participation on PM consultants' interpersonal abilities and consulting performance.

Next, moderated regression analysis was carried out to confirm moderating effects of client enterprises' level of participation in the relationship between PM management abilities and consulting performance concerning PM consultant competencies (Table 4).

Table 4. Moderating regression result on PM consultants' management abilities and consulting performance Model Summary

\begin{tabular}{|c|c|c|c|c|c|c|c|c|c|}
\hline \multirow[t]{2}{*}{ Model } & \multirow[t]{2}{*}{$\mathrm{R}$} & \multirow[t]{2}{*}{$\mathrm{R}^{2}$} & \multirow[t]{2}{*}{ Adj. $R^{2}$} & \multirow{2}{*}{$\begin{array}{l}\text { Estimated } \\
\text { SE }\end{array}$} & \multicolumn{5}{|c|}{$\Delta$ Statistics } \\
\hline & & & & & $\Delta \mathrm{R}^{2}$ & $\Delta \mathrm{F}$ & dfl & $\mathrm{df} 2$ & Significant Prob. $\Delta \mathrm{F}$ \\
\hline 1 & $0.755^{\mathrm{a}}$ & 0.571 & 0.569 & 0.59155 & 0.571 & 276.596 & 1 & 208 & 0.000 \\
\hline 2 & $0.796^{\mathrm{b}}$ & 0.633 & 0.630 & 0.54824 & 0.062 & 35.156 & 1 & 207 & 0.000 \\
\hline 3 & $0.836^{c}$ & 0.699 & 0.695 & 0.49767 & 0.066 & 45.207 & 1 & 206 & 0.000 \\
\hline
\end{tabular}

a. Predicted value: (Constant), PM management abilities

b. Predicted value: (Constant), PM management abilities, Level of participation

c. Predicted value: (Constant), PM management abilities, Level of participation, PM management abilities* Level of participation

ANOVA $^{\mathrm{d}}$

\begin{tabular}{|c|c|c|c|c|c|c|}
\hline \multicolumn{2}{|c|}{ Model } & Sum of Square & df & Avg. square & $\mathrm{F}$ & $\mathrm{p}$ \\
\hline \multirow[t]{3}{*}{1} & Regression Model & 96.788 & 1 & 96.788 & 276.596 & $0.000^{\mathrm{a}}$ \\
\hline & Residual & 72.785 & 208 & 0.350 & & \\
\hline & Total & 169.573 & 209 & & & \\
\hline \multirow[t]{3}{*}{2} & Regression Model & 107.355 & 2 & 53.678 & 178.587 & $0.000^{\mathrm{b}}$ \\
\hline & Residual & 62.218 & 207 & 0.301 & & \\
\hline & Total & 169.573 & 209 & & & \\
\hline \multirow[t]{3}{*}{3} & Regression Model & 118.552 & 3 & 39.517 & 159.553 & $0.000^{c}$ \\
\hline & Residual & 51.021 & 206 & 0.248 & & \\
\hline & Total & 169.573 & 209 & & & \\
\hline
\end{tabular}

a. Predicted value : (Constant), PM management abilities

b. Predicted value : (Constant), PM management abilities, Level of participation

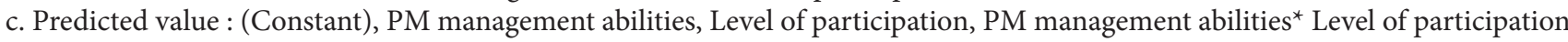

d. Dependent Variable : Consulting Performance 
Coefficient $^{\mathrm{a}}$

\begin{tabular}{|c|c|c|c|c|c|c|}
\hline & & \multicolumn{2}{|c|}{$\begin{array}{l}\text { Non Standardized } \\
\text { Coefficient }\end{array}$} & \multirow{2}{*}{$\begin{array}{c}\text { Standardized } \\
\text { Coefficient }\end{array}$} & \multirow[t]{2}{*}{$\mathrm{t}$} & \multirow[t]{2}{*}{$\mathrm{p}$} \\
\hline & & B & SE & & & \\
\hline \multirow[t]{2}{*}{1} & (Constant) & 0.504 & 0.210 & & 2.398 & 0.017 \\
\hline & PM management abilities & 0.836 & 0.050 & 0.755 & 16.631 & 0.000 \\
\hline \multirow[t]{3}{*}{2} & (Constant) & 0.779 & 0.200 & & 3.887 & 0.000 \\
\hline & PM management abilities & 0.696 & 0.052 & 0.629 & 13.307 & 0.000 \\
\hline & Level of Participation & 0.512 & 0.086 & 0.280 & 5.929 & 0.001 \\
\hline \multirow[t]{4}{*}{3} & (Constant) & 0.153 & 0.204 & & 0.749 & 0.455 \\
\hline & PM management abilities & 0.867 & 0.054 & 0.783 & 16.097 & 0.000 \\
\hline & Level of Participation & 3.765 & 0.490 & 2.060 & 7.681 & 0.000 \\
\hline & $\begin{array}{l}\text { PM management abilities } \\
{ }^{\star} \text { Level of Participation }\end{array}$ & -0.767 & 0.114 & -1.873 & -6.724 & 0.000 \\
\hline
\end{tabular}

a. Dependent Variable : Consulting Performance

Firstly, effects of independent variables on dependent variables were verified. The analysis of the effects of PM consultants' management abilities on consulting performance found 0.571 in R-squared value. This indicates that $57.1 \%$ of the total variation is explained by the regression model. PM consultants' management abilities exhibited 16.631 in $t$ value and 0.000 in significant probability for consulting performance. This implies that PM consultants' management abilities have a statistically significant influence on consulting performance. In this regard, the standardization factor was found to be 0.755 .

Secondly, multiple regression analysis was conducted for dummy variables of PM consultants' management abilities and client enterprises' participation to analyze an influence of independent variables and moderate variables on Dependent variables. The results found 0.62 in the variation of R-squared value, compared to that of R-squared value from the regression model of PM consultants' management abilities and consulting performance. This implies that $63.0 \%$ of the total variation is explained by the regression model with 0.0630 , an increase of 0.062 . At this point, PM consultants' interpersonal abilities were found to have a significant influence on consulting performance with 13.307 in $t$ value and 0.000 in significant probability. In this regard, the standardized coefficient was observed to be 0.629 . Client enterprises' level of participation was found to have a statistically significant influence on consulting performance with 5.929 in t value and 0.000 in significant probability. In this regard, the standardized coefficient was found to be 0.280 .

Lastly, analysis of effects on the dependent variable was carried out by adding independent variables, control variables, and interaction terms. As a result, the variation of the modified R-squared value from the multiple regression of independent variables and control variables previously analyzed turned out 0.066 , which means that $69.9 \%$ of the total variation is explained by the regression model with 0.699 , an increase of $6.6 \%$. At this point, PM consultants' management abilities were found to have a significant influence on consulting performance with 16.097 in $t$ value and 0.000 in significant probability. In this regard, standardized coefficient was 0.783. Additionally, the interaction between PM consultants' interpersonal abilities and client enterprises' participation showed -6.724 in $t$ value and 0.000 in $t$ value, which have a statistically significant influence on consulting performance. In this regard, standardized coefficient was found to be -1.873 . Therefore, in the process when PM consultants interpersonal abilities as a similar moderator variable having a significant effect on dependent variables, client enterprises' level of participation moderates consulting performance according their active or passive attitude. 
In short, in the process when PM consultants' competencies have a statistically significant influence on consulting performance, and client enterprises' participation moderates consulting performance according their active or passive attitude in Figure 3. Therefore, it is considered that both the hypothesis $\mathrm{H} 1$ that PM consultants competencies will have a positive influence on consulting performance and the hypothesis $\mathrm{H} 2$ that effects of $\mathrm{PM}$ consultants competencies will moderated according to client enterprises' participation have been supported.

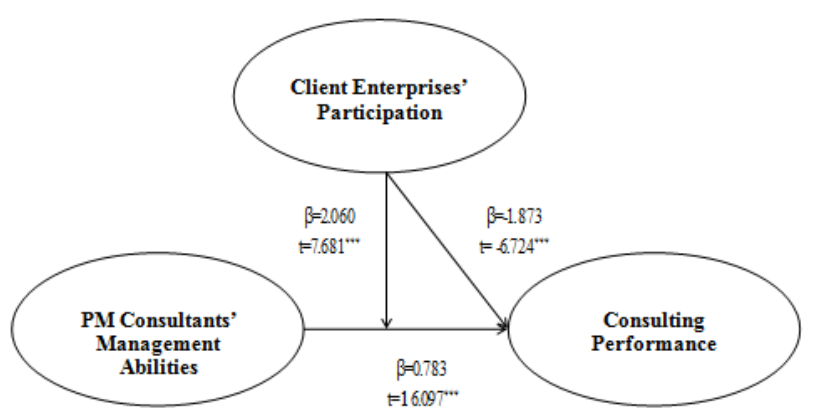

Figure 3. Moderating effects of level of participation on PM consultants' management abilities and consulting performance.
Next, for the last hypothesis $\mathrm{H} 3$ that consulting performance will have a positive $(+)$ influence on consulting satisfaction, regression analysis of consulting performance and consulting satisfaction was performed to verify the hypothesis $\mathrm{H}$. The results found that the fit of the regression model was statistically significant with 698.610 in F value and .000 in significant probability. In addition, the explanatory power explained by the R-squared value was observed to be .771 , which implies that the $77.1 \%$ of the total variation is explained by the regression model. In addition, consulting performance was found to have a statistically significant influence on consulting satisfaction with 26.431 in t value and .000 in significant probability (Table 5). It was thus confirmed that the hypothesis $\mathrm{H} 3$ that consulting performance will have a positive $(+)$ influence on consulting satisfaction has been supported.

\section{Conclusions}

Interpersonal abilities, including self-awareness, managing feelings, intuitions, opinions, persuasion effort, motivation, and integrity, and management abilities, including resources management, communication, empowerment, team development, and determination

Table 5. Regression result on consulting performance and consulting satisfaction Model Summary

\begin{tabular}{|l|c|c|c|c|}
\hline Model & $\mathrm{R}$ & $\mathrm{R}^{2}$ & Adj. $^{2}$ & Estimated SE \\
\hline 1 & $0.878^{\mathrm{a}}$ & 0.771 & 0.769 & 0.48575 \\
\hline
\end{tabular}

a. Predicted value : (Constant), Consulting Performance

\begin{tabular}{|l|l|c|c|c|c|c|}
\hline \multicolumn{2}{|c|}{ Model } & Sum of Square & df & Avg. square & F & p \\
\hline \multirow{3}{*}{1} & Regression Value & 164.841 & 1 & 164.841 & 698.610 & $0.000^{\mathrm{a}}$ \\
\cline { 2 - 7 } & Residual & 49.079 & 208 & .236 & & \\
\cline { 2 - 7 } & Total & 213.920 & 209 & & & \\
\hline
\end{tabular}

a. Independent Variable : (Constant), Consulting Performance

b. Dependefnt Variable : Consulting Satisfaction

Coefficient $^{\mathrm{a}}$

\begin{tabular}{|l|l|c|c|c|c|c|}
\hline \multicolumn{2}{|c|}{} & \multicolumn{2}{c|}{$\begin{array}{c}\text { Non Standardized } \\
\text { Coefficient }\end{array}$} & $\begin{array}{c}\text { Standardized } \\
\text { Coefficient }\end{array}$ & \multirow{2}{*}{ t } \\
\cline { 2 - 6 } \multicolumn{2}{|c|}{} & B & SE & $\beta$ & & 0.555 \\
\hline \multirow{2}{*}{1} & (Constant) & -0.089 & 0.151 & & -0.592 & 0.000 \\
\cline { 2 - 6 } & $\begin{array}{l}\text { Consulting } \\
\text { Performance }\end{array}$ & 0.986 & 0.037 & 0.878 & 26.431 & \\
\hline
\end{tabular}

b. Dependent Variable : Consulting Satisfaction 
have an influence on consulting performance, including period, compliance, whether carried out or not within the budget, achieving goals of consulting, actual utilization degree of consulting, contribution to corporate profits, and overall success of consultation carry-out.

Therefore, bothinterpersonal abilities and management abilities are considered important to ensure PM consultants being input experience consulting performance and consulting satisfaction in terms of the consulting supporting project funded by the government. In addition, seeing that the current recruiting system, which is allowed to select consulting agencies retaining management consultants or technical instructors selected in the Small and Medium Business Administration, or licensed consultants, does not have separate selection criteria, thus, institutional complement should be made up for to bring about expected effects from the government-funded consulting supporting project implemented for the purpose of raising competitiveness of SMEs.

\section{Acknowledgement}

This research was financially supported by Hansung University.

\section{References}

1. Kim EH, Kim HY. An influence of project managers' competency and leadership types on project performance and customer satisfaction. Journal of the Korean Operations Research and Management Science Society. 2006; 31(4):157-79.

2. Han YO. An influence of project competencies on project performance. Soongsil University; 2007. p. 51.

3. Boyatzis RE, Ratti F. Emotional, social, and cognitive intelligence competencies, distinguishing effective Italian manager and leaders in a private company and cooperatives. Journal of Management Development. 2009; 28(9):821-38.

4. Lee HJ, Park JG, Lee JW. Leadership competencies of IT project managers. Journal of the Korea Society of IT Services: Social Capital in Team. 2011; 10(4): 133-47.

5. Jang DI. A study of effects of consultants' competencies on consulting performance by means of service quality. Kyoung Hee University; 2011. p. 29-34.

6. Han JH. The impact of leadership on individual creativity and organizational innovation. Indian Journal of Science and Technology. 2015; 8(24):2-3.

7. Choi YS. An influence of consult competencies on customer satisfaction and renewal intentions. Komoh National Institute of Technology; 2012. p. 1-61.

8. Moon HS. A study of small and medium businesses' participation on consulting performance and reuse. Hansung University; 2012.

9. Shim JS. A study of consulting on satisfaction and performance in small and medium businesses; 2012.

10. Yook HY. An influence of consulting key elements on consulting performance in small-medium seized companies. Hansung University; 2013. 